\title{
Diversidade étnica e cultural na escola de educação básica
}

\section{Luciane Weber Baia Hees ${ }^{1}$ Germana Ponce de Leon Ramírez²}

Resumo: Neste artigo, buscou-se analisar as ações da gestão escolar acerca da valorização da diversidade étnica e cultural em duas escolas públicas no interior do estado de São Paulo, relacionando as reflexões de Paulo Freire à questão da diversidade cultural. Destaca-se a responsabilidade da escola diante das desigualdades intraescolares e ações a serem implementadas pela gestão em combate às ações discriminatórias. Assim, indaga-se: Qual a atuação da escola diante da discriminação étnica no espaço escolar? Trata-se de um estudo qualitativo e exploratório; usa-se a entrevista a três gestores escolares da rede pública como instrumento de coleta de dados. Com base nos dados da pesquisa identifica-se a necessidade de ações pontuais e sistemáticas nos currículos escolares para lidar com as questões étnico-raciais, inclusive na formação inicial e continuada dos gestores. Enfatiza-se o legado dos pressupostos deixados por Paulo Freire como humanista e sua proposta às práticas pedagógicas que valorizam a multiculturalidade. Alerta-se acerca da necessidade de se atuar de forma sistemática diante de uma escola que está inserida numa sociedade racista e preconceituosa.

Palavras-chave: diversidade étnica; gestão escolar; educação básica.

\section{Cultural and ethnic diversity at the school of basic education}

Abstract: This article sought to analyze the actions of school management about the valorization of ethnic and cultural diversity in two public schools in the interior of the state of São Paulo, relating Paulo Freire reflections about the issue of cultural diversity. The responsibility of the school in the intra-school inequalities and actions to be implemented by management in combating discriminatory actions stands out. Thus, the question is: what is the action of the school in the face of ethnic

\footnotetext{
1 Doutora em Psicologia da Educação pela Pontifícia Universidade Católica de São Paulo (PUC-SP). Professora permanente do Mestrado Profissional em Educação do Centro Universitário Adventista de São Paulo, campus Engenheiro Coelho (Unasp-EC). E-mail: luciane.hees@unasp.edu.br

2 Doutora em Geografia Humana pela Universidade Federal de Santa Catarina (UFSC). Professora permanente do Mestrado Profissional em Educação do Centro Universitário Adventista de São Paulo, campus Engenheiro Coelho (Unasp-EC). E-mail: germana.ramirez@unasp.edu.br
} 
discrimination in the school space? This is a qualitative and exploratory study; the interview is used as a data collection tool for three school managers in the public school system. Based on the research data, the need for specific and systematic actions in school curriculum to deal with ethnic-racial issues is identified, including the initial and continued training of managers. It emphasizes the legacy of the assumptions left by Paulo Freire as a humanist and his proposal to pedagogical practices that value multiculturalism. It warns about the need to act systematically in front of a school that is inserted in a racist and prejudiced society.

Keywords: ethnic diversity; school management; basic education.

As questões acerca da diversidade étnica e a discussão sobre essa temática no âmbito escolar têm sido palco de calorosos debates em nível nacional e internacional. Mas no que tange ao espaço brasileiro tem-se um panorama cujas discussões permeiam um pensamento eurocêntrico e, portanto, preconceituoso (RAMÍREZ; SILVA, 2019).

Conforme Ramírez (2019), o brasileiro comumente não se vê miscigenado, mesmo sendo possuidor de um fenótipo dominante. Ele se refere ao outro como sendo negro ou indígena, mas a ele não é agregada essa ascendência, mesmo sendo conhecedor da história da formação do povo brasileiro. Desse modo, percebe-se que é necessário trazer para o espaço escolar esse debate, e isso pode ser possível quando a gestão percebe a necessidade de combater as ações discriminatórias no ambiente escolar. E entendendo que essa discussão é abrangente, mas necessária, este trabalho tem como objetivo analisar como se dá a conscientização da gestão escolar acerca da valorização da diversidade étnica e cultural em duas instituições de ensino público no interior do estado de São Paulo.

A conscientização da origem étnica pode iniciar-se por meio da valorização da diversidade e não pelo desprezo ou fortalecimento de ideias estereotipadas e preconceituosas. Dessarte, entende-se que o espaço escolar pode ser um espaço para essa conscientização. E é mediante pilares calcados em combater as ações discriminatórias e a desvalorização do outro que poderá ser possível colher mudanças de uma sociedade que se valoriza, que se aceita com orgulho e desfruta da diversidade étnica como um bem cultural (CARVALHO; FRANÇA, 2019).

Ao se refletir sobre respeito à diversidade étnica e cultural, considerou-se fundamental atentar para a natureza humanista e dialética do pensamento de Paulo Freire. Os conceitos difundidos por Freire foram extraídos de sua experiência pessoal e do seu olhar para a realidade. A partir desse contexto histórico-cultural da realidade, o educador brasileiro estabeleceu seu discurso político-pedagógico, do qual pode-se extrair categorias como "humildade, diálogo e respeito, que são imperativas para uma prática educativa da tolerância significativamente eficaz para um humanismo pedagógico transcultural" (PEROZA et al., 2013, p. 462). 
Destarte, este trabalho se desdobra em quatro partes. A primeira aponta a metodologia desenvolvida nesta pesquisa. Em seguida, tem-se uma explanação acerca da importância da discussão sobre a diversidade étnica no âmbito educacional. A posteriori é comentado sobre o papel da gestão escolar nesse contexto da conscientização e combate à discriminação. Por fim, a conclusão.

\section{Metodologia}

Este trabalho é de cunho qualitativo. Segundo Lüdke e André (1986), a pesquisa qualitativa tem o ambiente natural como sua fonte direta de dados e o pesquisador como seu principal instrumento; os dados coletados são descritivos; a preocupação com o processo é maior do que com o produto; o significado que as pessoas dão as coisas é foco de estudo; a análise dos dados segue um processo indutivo.

Para a coleta de dados primários utilizou-se a entrevista semiestruturada, por constituir um instrumento que possibilita captar as visões dos sujeitos sobre sua prática. Esse tipo de entrevista tem como característica esclarecer aspectos básicos relacionados ao objeto de estudo. A partir das respostas, novos questionamentos podem ser levantados, e esse tipo de entrevista "favorece não só a descrição dos fenômenos sociais, mas também sua explicação e a compreensão de sua totalidade" (TRIVIÑOS, 1987, p. 152).

A pesquisa ficou limitada a duas instituições de ensino público no interior do estado de São Paulo. A escolha desse campo para pesquisa se deve ao fato de as pesquisadoras terem acesso às escolas dessa cidade por contribuírem com projetos comunitários e sociais. Dessa maneira, o encontro para a entrevista foi marcado pessoalmente com os três gestores. Após um posicionamento positivo por parte de cada um deles, foram marcados o dia, local e horário para a entrevista. O local foi a própria escola de educação básica. Os horários e os dias foram estabelecidos de acordo com a disponibilidade de cada um.

O delineamento da entrevista foi organizado em torno de seis questões principais (roteiro básico) que focaram sobre a existência de crianças negras na instituição, a existência de brincadeiras de mau gosto e discriminação com crianças negras e o levantamento de atividades realizadas na escola para prevenir essas situações com alunos, professores e comunidade.

Após a coleta de dados foi realizada uma leitura flutuante das entrevistas, que é um termo usado por Bardin (2016) para designar o primeiro contato com os documentos, com o objetivo de levantar hipóteses ou temáticas relacionadas à investigação. Foram identificados três focos de análise que se relacionavam com os objetivos da pesquisa: 1) aspectos relativos à discriminação racial nas escolas; 2) intervenções adotadas pela instituição e 3) relações instituídas entre a escola e a comunidade. É importante informar que esta pesquisa foi submetida e aprovada pelo comitê de ética por meio da Plataforma Brasil sob o protocolo de n².298.444. 


\section{A conscientizacão como ato de combate à discriminação étnica}

A conscientização acerca da diversidade étnica perpassa por um debate cuja origem foi construída ao longo de séculos e conceitos foram criados nesse sentido, embasando uma ideia hierarquizada dos grupos sociais humanos. Dessa maneira, são essenciais o conhecimento, a reflexão e a tomada de decisão em se tratando de diversidade étnica e cultural. E essa oportunidade, tanto de participar quanto de proporcionar as reflexões e conhecimentos, tem como espaço propício a escola (RAMÍREZ; GONÇALVES; ANDRADE, 2019).

Desse modo é considerável que haja conhecimento e tomada de decisão por parte da gestão para qualificar os professores e alunos no sentido de esclarecer acerca das ações discriminatórias, das situações de desvalorização que existem nas relações sociais, nos meios midiáticos, nos materiais didáticos, entre outros. Pois, como diz Munanga (2005), existe um despreparo calcado na democracia racial que acaba comprometendo a missão no processo de formação de futuros cidadãos responsáveis, valorosos e respeitosos.

Jones (1973) ressalta que há uma visão negativa do negro, e este é representado na maior parte desses meios sob uma perspectiva negativa. Outro ponto é a comparação que se estabelece entre grupos sociais distintos, sem considerar as diferenças existentes. Isso acaba por incentivar a exclusão étnica, a falta de reconhecimento da identidade e o respeito ao outro.

Tanto a história dos afrodescendentes quanto dos povos indígenas no contexto brasileiro é trabalhada de forma superficial, visto que poucos apresentam a participação desses atores sociais como sendo de importância ou utilizando uma abordagem sem uma visão eurocêntrica. Como, por exemplo, a imagem do negro que é comumente apresentada como escravo ou em status social inferiorizado, não sendo um exemplo de beleza ou destaque (BRASIL, 2006; VALENTE, 1994).

É significativo evidenciar que a escola, antes de trabalhar as relações ético-raciais (temática que se encontra inserida no currículo), deve proporcionar um preparo e capacitação aos docentes no sentido de oferecer espaço para discussão dos assuntos inter-raciais, juntamente com o apoio da gestão escolar para a abordagem eficaz dos conteúdos. Dado que não se deve trabalhar aquilo que não se conhece, é preciso ter conhecimentos adequados e cautela para a abordagem da diversidade étnica, para que não haja prejuízo para os alunos diante dessas questões (LIMA, 2004).

Os alunos e professores precisam obter conhecimentos que provoquem a discussão sobre a questão racial dentro do espaço escolar. Afinal de contas, essas políticas devem visar à inclusão e possibilitar conhecimento para que haja respeito e valorização dos elementos culturais brasileiros no processo de ensino e aprendizagem (RAMíREZ, 2019).

Ao pensar sobre as questões raciais dentro das escolas, muitos professores criam uma verdadeira barreira no que diz respeito à forma como enxergam os seus alunos negros ou indígenas. É possível 
que esse profissional possa falar sobre racismo aos alunos, mas quando ele é rejeitado, excluído ou despercebido, cria-se comportamentos de vergonha e comparações estereotipadas. Isso gera vergonha nesse aluno, como também medo de aparecer e, por conseguinte, comportamentos negativos diante dessa temática (SILVA, 1995).

Muitas vezes a ideia de preconceito vai se desenvolvendo no interior da própria pessoa que é negra ou indígena, porque essa diversidade étnica, comumente, não é mostrada como importante dentro do âmbito escolar. A cultura afro-brasileira e a diversidade cultural da África e dos povos indígenas acabam não sendo trabalhadas de modo amplo e adequado. Em contrapartida, tem-se o reforço da ideia de branqueamento, e isso se encontra presente em muitos recursos que o educador utiliza dentro de sala de aula. Por consequência, a imagem negativa dessa diversidade étnica vai se perpetuando e ganhando espaço (SILVA, 2005).

Dentre os recursos utilizados pelo professor em sala de aula tem-se o livro didático, que é um dos meios mais usados no processo de ensino. É uma ferramenta utilizada pela maioria das instituições de ensino que contém uma postura de discriminação e, principalmente, a discriminação racial. É um requisito, nesses materiais, aparecer o contexto histórico-cultural de diferentes etnias, porém, quando é apresentada a questão afro-brasileira, comumente, sua representação é de uma maneira estereotipada; a presença do negro é genérica e anônima, arruinando sua autoestima e identidade (SILVA, 1995).

Conforme a Lei 11.645 de 2008, é dever da escola cumprir as normas que regem o estabelecimento do ensino da história da cultura africana, afro-brasileira e acerca dos povos indígenas; que vise mostrar a imagem positiva do negro na progressão de valores, tradições, cultura e o respeito para uma sociedade democrática sem omissão e injustiça de desigualdades. Em vista disso, o educador deve receber apoio sistemático para a abordagem dos temas, que não são abordados de forma amplamente precisa nos livros didáticos, dando continuidade ao trabalho em busca de ampliar os temas aos saberes dos alunos por meio de projetos e métodos inovadores como foco da história e cultura afro-brasileira.

Para isso, é necessário que as instituições cumpram com o dever de saber lidar com questões que envolvam preconceito racial entre indivíduos e o que se encontra presente em materiais explorados pelo educador. Tudo isso em função de ensinar a equidade de cidadania e respeito mútuo. Ao pensar sobre contextualizar o ensino voltado para as relações étnico-raciais, são fundamentais a valorização e o reconhecimento dos alunos sobre a diversidade e história cultural brasileira. O objetivo é induzir na conscientização dos alunos os direitos iguais e a importância dos grupos éticos para a cultura brasileira (AZEVEDO, 2011; BRASIL, 2009).

Segundo a fala dos três gestores, a presença de crianças negras é considerável em todas as duas instituições de ensino pesquisadas. O Instituto Brasileiro de Geografia e Estatística (IBGE), em 2016, re- 
gistrou que a população brasileira chegou a 205,5 milhões de habitantes e os brancos deixaram de ser maioria, representando $44,2 \%$. Os pardos passaram a representar a maior parte da população (46,7\%), e os pretos são $8,2 \%$ do total de brasileiros. Segundo o IBGE, os negros (pretos e pardos) compõem a maioria da população brasileira, representando $53,6 \%$ da população.

Apesar de o afro-brasileiro representar a maior parte da população brasileira, a incidência de discriminação, apontada pelos três gestores em todas as escolas e em todos os segmentos, a saber, da educação infantil ao fundamental II, evidencia a necessidade de serem realizados mais projetos de intervenção e a busca de estratégias mais pontuais para conscientização do respeito racial pela comunidade escolar.

O conceito de educação dialógica de Freire continuou a ser usado pelos teóricos críticos argumentando que na escola, e por meio do currículo, os estudantes devam ter a oportunidade de desenvolver o exercício permanente da discussão e da participação, levando ao questionamento dos pressupostos do senso comum da vida social, revendo preconceitos, estereótipos e atitudes discriminatórias, assim como revendo a construção de representações do mundo e da sociedade. Questionando, em última análise, as condições que geram as injustiças sociais e buscando alternativas para acabar com elas (MARCONDES, 2018, p. 979).

Portanto, é necessário que a gestão escolar permita a participação de todos nas tomadas das decisões escolares, e o envolvimento da coordenação pedagógica é de grande valia no sentido de favorecer a reflexão no combate à discriminação étnica e cultural. Além disso, a gestão escolar deve interferir diretamente nessa luta, para que a herança negativa que o afro-brasileiro carrega seja repensada, diluída e exterminada ao longo do tempo. Com base na coleta de dados, junto aos três gestores, identifica-se no âmbito escolar das duas instituições de ensino que há brincadeiras que evidenciam a discriminação racial. Eles exemplificaram situações dizendo que ouvem as crianças falarem para seus colegas termos como "macaco, negrinho", cabelo de miojo, e dizem frases como: "tinha que ser negro para fazer isso, entre outras falas".

\section{Ógestor diante da discriminação étnica no espaço escolar}

A Carta Magna brasileira assevera, a partir do artigo 205, os principais atributos e objetivos da educação, a saber: "A educação, direito de todos e dever do Estado e da família, será promovida e incentivada com a colaboração da sociedade, visando ao pleno desenvolvimento da pessoa, seu preparo para o exercício da cidadania e sua qualificação para o trabalho."

A educação escolar compromete a formação do cidadão e o exercício consciente da cidadania. Trata-se de um direito reconhecido; entretanto, é preciso que seja efetivamente garantido. Vislum- 
bra-se, portanto, o papel da gestão escolar de assumir e assegurar a concretização desse direito no âmbito de suas atribuições. Quem assevera essa ideia é Cury (2007) ao dizer que

A declaração e a efetivação desse direito tornam-se imprescindíveis no caso de países, como o Brasil, com forte tradição elitista e que, tradicionalmente, reservaram apenas às camadas privilegiadas o acesso a este bem social. As precárias condições de existência social, os preconceitos, a discriminação racial e a opção por outras prioridades fazem com que tenhamos uma herança pesada de séculos a ser superada (CURY, 2007, p. 484).

A "Convenção relativa à Luta contra a Discriminação no campo do Ensino", estabelecida em 14 de dezembro de 1960 pela Conferência Geral da Organização das Nações Unidas para a Educação, a Ciência e a Cultura (Unesco), em Paris, assinala no artigo IV que devem ser tomadas medidas para lutar contra os diversos aspectos da discriminação no ensino, assegurando a igualdade de oportunidade e de tratamento. No início do documento, o artigo I explica que

Para os fins da presente Convenção, o termo discriminação abarca qualquer distinção, exclusão, limitação ou preferência que, por motivo de raça, cor, sexo, língua, religião, opinião pública ou qualquer outra opinião, origem nacional ou social, condição econômica ou nascimento, tenha por objeto ou efeito destruir ou alterar a igualdade de tratamento em matéria de ensino (UNESCO, 1960, p. 3).

O artigo $5^{\circ}$ do Estatuto da Criança e do Adolescente (ECA) determina que nenhuma criança pode ser objeto de qualquer forma de discriminação, e no artigo 16, que participar da vida comunitária sem discriminação é um direito. E por fim, no artigo 58 do mesmo dispositivo legal lemos que "no processo educacional respeitar-se-ão os valores culturais, artísticos e históricos próprios do contexto social da criança e do adolescente, garantindo-se a estes a liberdade da criação e o acesso às fontes de cultura".

Gadotti (1995, p. 83) afirma que "a força da educação está no seu poder de mudar comportamentos. Mudar comportamentos significa romper com certas posturas, superar dogmas, desinstalar-se, contradizer-se". Paulo Freire (1987) chama a atenção para a necessidade de o oprimido, ao se reconhecer como tal e identificar o opressor, organizar-se em luta por sua libertação. É nesse processo que o oprimido passa a acreditar em si mesmo, criando a possibilidade de superação de sua condição.

Vaz (2008) assevera que o espaço escolar necessita de ação e não apenas de reflexão sobre as diferenças sociais e a diversidade sociocultural. É preciso agir para não correr o risco de se deter apenas nas reflexões acerca das diferenças socioculturais. E nessa direção

Talvez a grande questão seja saber em que reside a diferença, uma vez que ser diferente coloca necessariamente um campo relacional, de forma que a linha a separar um posicionamento do outro, primeiro pode ser vista como um abismo; porém, muitas vezes, é quase tão tênue, que nem a avistamos. Pelo contrário, caminhamos sobre ela (BASTIANI, 2000, p. 173). 
A necessidade de mudanças se mostra como uma possibilidade de oferecer alternativas para buscar soluções e construir a escola que se precisa ter e essa construção se faz por meio das relações humanas. Dessa forma, os gestores devem mobilizar e estimular o desenvolvimento da aprendizagem para o exercício de uma cidadania competente. Cabe aos gestores zelar pela realização dos objetivos educacionais, para alcançar os padrões de qualidade e o cumprimento das leis nacionais, estaduais e municipais, bem como encontrar meios para a promoção de ações educacionais com qualidade social. Isso quer dizer que, ao prestar os serviços educacionais, a escola deve fazer isso atendendo bem à comunidade escolar e local, considerando e preservando as diferenças de todos os seus alunos, promovendo o acesso e as práticas educacionais de forma participativa (SILVA; RAMIREZ, 2020).

Freire (1987) ressalta a importância da ação participativa por parte de todos de forma igualitária e não opressora, já que na conjuntura social o opressor impõe uma desigual relação quando exclui a participação do oprimido. Diante do pensamento de Paulo Freire, é possível dizer que se faz necessário conduzir o processo educativo de tal forma que a comunidade envolvida se sinta parte do processo, porque ela realmente faz parte do contexto, mas de forma plena e integrada. $O$ aluno, nessa conjuntura, poderá se tornar um cidadão atuante e transformador da realidade sociocultural.

O gestor escolar tem um caráter abrangente, porque, além de incentivar a participação de todos os sujeitos no espaço escolar, é responsável, juntamente com sua equipe administrativa, pela parte pedagógica, educacional, burocrática e técnica. Essa amplitude de abrangência da função do gestor engloba todos os aspectos possíveis que possam favorecer a qualidade de aprendizagem para todos os alunos e o cumprimento da Lei no 10.636/03 e do Estatuto de Igualdade Racial.

O Estatuto de Igualdade Racial (2010) é um reflexo da reação após se perceber a opressão daqueles que tiveram uma história de discriminação étnica ao longo dos séculos no contexto brasileiro. Esse estatuto vem reafirmar a busca pela mudança social referida por Paulo Freire na obra Pedagogia do oprimido, quando se afirma sobre a busca por uma sociedade mais humanizada. Entretanto, vale salientar que a existência do referido estatuto não mostra que há uma consciência e busca por uma liberdade nesse âmbito opressor de fato, mas que se caminha em busca dessa mudança social, mesmo que a passos lentos.

Desse modo, a gestão escolar precisa gerenciar toda a dinâmica cultural da escola. Em coerência com as diretrizes educacionais e políticas públicas, alcançaremos a necessidade de o gestor estar atento com sua responsabilidade de elaborar meios que organizem e criem um ambiente educacional de participação, com autonomia e espaço para todos os alunos, professores e comunidade. Preconceitos concebidos estão inseridos no ambiente escolar, e cabe ao gestor incentivar discussões étnico-raciais e a construção de estratégias para atender o que prevê a Lei n. 10.636/03. 
Daí a necessidade imediata de educadores e educandos se articularem, a fim de estabelecer redes de convivência que resultem não só no ensino-aprendizagem de determinados saberes, mas, para, além disso, na percepção e na aceitação da importância de outras tantas maneiras de viver e de saber (PEREIRA, 2007, p. 15).

O gestor escolar, além da mobilização das pessoas para a realização eficaz das atividades, define os rumos educativos, sendo o grande elo integrador, articulador dos vários segmentos, cuidando da gestão das atividades e da própria escola (VASCONCELLOS, 2002). Nesse quadro, cabe a necessidade de promover a organização, a mobilização e a articulação de todas as condições materiais e humanas para garantir o avanço dos processos sócio-educacionais dos estabelecimentos de ensino. Entende-se que isso envolve a necessidade da proteção e manutenção da igualdade e da aceitação das diversidades étnicas raciais no espaço escolar.

Ademais, entende-se que isso pode ser efetivado através da mobilização e conscientização de todos os envolvidos. Mas isso é suficiente para sustentar e dinamizar a cultura das escolas, para respeitar e valorizar as diferenças raciais? Que ações conjuntas, associadas e articuladas estão sendo desenvolvidas nas escolas para valorização e respeito étnico-racial? Ou será que as iniciativas são poucas, isoladas e buscam soluções tópicas, localizadas, quando de fato os problemas são mais enraizados e inter-relacionados?

Freire (1987) reafirma que é preciso atentar-se para que aquele que é oprimido não se torne o opressor do opressor, mas, por meio de conscientização e preparo, no que tange à luta pela humanização, é que a sociedade pode ser transformada. Nesse cenário a gestão escolar constitui uma dimensão fundamental da educação, uma vez que através dela, tem-se uma visão ampla da escola e dos problemas educacionais e deve-se buscar pelo planejamento estratégico e ações interligadas, a aprendizagem efetiva e significativa dos alunos, tomando decisões fundamentadas e resolvendo conflitos. Segundo Munanga (2005, p. 18), precisamos "despojarmo-nos do medo de sermos preconceituosos e racistas e saber que, é o outro [sic] no processo de produção de identidade, conciliar escola, currículo e educação étnico-racial".

A dimensão do conceito de gestão educacional abrange uma série de concepções não abarcadas pela administração. Pode-se mencionar: a democratização do processo de determinação dos destinos do estabelecimento de ensino e seu projeto político pedagógico; a compreensão da dinâmica das relações interpessoais da organização, o entendimento dessa organização como uma entidade viva, demandando uma atuação especial de liderança; o entendimento de que a mudança dos processos pedagógicos envolve alterações nas relações sociais da organização; a compreensão de que os avanços se assentam muito mais em seus processos sociais do que sobre insumos ou recursos (LÜCK, 1997, p. 4-5).

Com base na aplicação da entrevista semiestruturada aos três gestores das duas instituições públicas de ensino no interior do estado de São Paulo, a presença de crianças negras é significativa 
nas duas instituições pesquisadas. Apesar de o afro-brasileiro representar a maior parte da população brasileira, como é mostrado por pesquisa do IBGE já mencionada neste artigo, há incidência de discriminação, apontada pelos três gestores nas escolas e em todos os segmentos, a saber, da educação infantil ao fundamental II. Diante disso, evidencia-se a necessidade de serem realizados mais projetos de intervenção de uma busca de estratégias mais pontuais para conscientização do respeito racial pela comunidade escolar.

É importante que a gestão permita a participação de todos nas tomadas das decisões escolares, e o envolvimento da coordenação pedagógica é de grande valia no sentido de favorecer a reflexão no combate à discriminação étnica e cultural. E ainda, que isso interfira diretamente nessa luta, para que a herança negativa que o afro-brasileiro carrega seja repensada, diluída e exterminada ao longo do tempo (SILVA; RAMÍREZ, 2020).

Como já mencionado, ainda com base na coleta de dados junto aos três gestores entrevistados, identifica-se, no âmbito escolar das duas instituições de ensino, que há "brincadeiras" que evidenciam a discriminação racial e os respondentes exemplificaram situações dizendo que ouvem as crianças falarem para seus colegas afro-brasileiros termos que estigmatizam como, por exemplo: macaco, negrinho, cabelo de miojo, e dizem frases como: tinha que ser negro para fazer isso, entre outras falas que são a expressão da violência instaurada nas instituições de ensino.

Souza (2008) ressalta a importância de refletir sobre a violência das instituições públicas, que deveriam garantir direitos, entretanto, muitas vezes passam a ser obstáculo no processo de acesso a esses direitos. Ou ainda acerca da violência simbólica inserida no contexto da educação, entre outros, que se configura como tendo pessoas que "tendem a aceitar condições injustas ou inadequadas e a naturalizar relações desiguais" (SOUZA, 2008, p. 14).

Sob a perspectiva das ideias de Arendt (1999), é possível perceber o que ela chama de Banalidade do Mal. Afinal, o mal é produzido pelos seres humanos e manifestado em um espaço, e esse mal é geralmente banalizado. Dentre esses espaços está o educacional, que pode ser cruel em se tratando da falta de respeito à diversidade étnica ou ainda pelo fato de ser permissiva diante de ações discriminatórias.

Os dados coletados por meio da entrevista semiestruturada com três gestores das duas instituições púbicas de ensino mostram que existem seis tipos de intervenções e projetos em combate a discriminação nessas instituições, os quais estão descritos no quadro a seguir: 


\begin{tabular}{|l|}
\hline \multicolumn{1}{|c|}{ Intervenções realizadas } \\
\hline - $\quad$ Eventos e atividades especiais na escola durante a semana da cons- \\
ciência negra. \\
- $\quad$ Advertência coletiva quando ocorre algum problema no grupo. \\
alunos e professores a importância de respeitar as diferenças e \\
como os negros fazem parte da história do Brasil. \\
- Programação no ginásio da cidade com manifestações culturais e \\
palestras na semana da consciência negra. \\
Orientação aos professores nas reuniões de Horário de Trabalho \\
Pedagógico Coletivo (HTPC) sobre o que deve ser falado e cada um \\
aborda o que considera mais eficaz. \\
Uma apostila sobre discriminação para ser trabalhada pelos profes- \\
sores de artes com os alunos.
\end{tabular}

Fonte: entrevista realizada pelas pesquisadoras com os gestores

Diante do que foi descrito no quadro, pode-se observar que excluindo as atividades específicas realizadas na semana da consciência negra devido ao dia 20 de novembro, os gestores mencionaram adotar a advertência coletiva. Entretanto, projetos como o referido pelo gestor são ações mais relevantes e efetivas, pois atendem o princípio constitucional da educação nacional, que é a garantia do padrão de qualidade através da participação e envolvimento de todos. Apenas dessa forma é possível "inventar as estratégias educativas e pedagógicas de combate ao racismo" (MUNANGA, 2005, p. 18).

Quanto às advertências coletivas, reforça-se que perceber o preconceito se torna fundante para possibilitar a superação de atos de racismo no ambiente escolar. Entretanto, identificar as causas através de uma investigação mais aprofundada é primordial para que o comportamento discriminatório não seja eliminado por medo, mas por conscientização e entendimento de igualdade e respeito. Alerta-se que as advertências coletivas podem não surtir o efeito esperado e acarretar a intensificação das diferenças.

Uma ação mais pontual foi a elaboração de uma apostila utilizada pela professora de artes do ensino fundamental I. Apostilas como essa podem oferecer experiências inovadoras dentro da escola, desmitificando e tornando conhecida a cultura, costumes e tradições de diferentes etnias e atendendo às exigências das Diretrizes Curriculares Nacionais para a Educação das Relações Étnico-Raciais e para o ensino de História e Cultura Afro-Brasileira e Africana, a saber:

O sucesso das políticas públicas de Estado, institucionais e pedagógicas, visando a reparações, reconhecimento e valorização da identidade, da cultura e da história dos negros, depende necessariamente de condições físicas, materiais, intelectuais e afetivas favoráveis para o ensino e para aprendizagens; em outras palavras, todos os alunos negros e não negros, bem como seus professores, precisam sentir-se valorizados e apoiados (BRASIL, 2007, p. 29). 
Apesar de ser uma ação isolada, essa apostila favorece a inserção de temas referentes às culturas africanas e afro-brasileiras nos currículos, permitindo conhecer "as influências que exerceram e continuam a exercer sobre a nossa sociedade" (AGUESSY, 1977, p. 126).

Outra intervenção mencionada foram as orientações dadas aos professores em reuniões com a coordenadora pedagógica; todavia, não foram explicitadas e identificadas práticas decorrentes dessas orientações. Entretanto, aqueles que estão lidando com crianças na escola certamente se deparam com racismo e preconceito, por isso precisam discutir e se aprofundar um pouco mais nessa temática. Mas, de qualquer forma, presenciando ou não essas situações, é fundamental o conhecimento desses conceitos, pouco discutidos e até mesmo evitados por conveniência ou por reforçar paradigmas que ainda são difíceis de serem superados. É fundamental "juntos construir novos conhecimentos num processo de trocas constantes, desmistificando situações de racismo, preconceito e discriminação" (LOPES, 2005, p. 189).

Sobre as relações instituídas entre a escola e a comunidade, nota-se a resistência de serem realizados projetos fora dos muros da escola. Isso pode ser identificado nas seguintes falas dos gestores entrevistados:

É trabalhoso, mas a escola deveria fazer; é difícil os pais participarem, principalmente os que mais precisam não participam (GESTOR 1, 2018).

A escola precisa mobilizar a comunidade para diversas questões, inclusive sobre o respeito racial. Desenvolvendo um papel social, influenciando seus alunos, professores e familiares estaremos contribuindo para isso (GESTOR 2, 2018).

Sim, com certeza é importante a escola conscientizar a comunidade, mas tem que ser a partir da Secretaria da Educação, porque envolve pais, abertura da escola em outros horários. Só não sei se os pais iriam vir, eles não costumam participar dessas coisas (GESTOR 3, 2018).

Os gestores admitem a necessidade de mobilizar a comunidade externa, não só a que está dentro do espaço escolar, mas se demonstram resistentes a tomarem a iniciativa, por não acreditarem no envolvimento dos pais, ou mesmo por afirmarem que esse papel caberia à Secretaria de Educação do município. Quando Freire (1987) fala em pedagogia, ele não está se referindo apenas às relações que se estabelecem na escola e na sala de aula. A pedagogia de Freire está relacionada a todo o contexto de opressão social. Não apenas a opressão das relações que se estabelecem na escola, mas uma práxis que propõe a libertação da opressão que predomina na nossa sociedade.

A escola tem um papel fundamental na formação do cidadão, por isso não pode se colocar como indiferente à discriminação que é mascarada no ambiente escolar (CARENO, 2009; LOPES, 2005). Cada vez mais explícitos nas escolas, esses estereótipos comprometem "as práticas pedagógicas marcadas pela homogeneização e pelo caráter monocultural" (CANDAU, 2009). 


\section{Considerações finais}

Salienta-se que quando a discriminação étnica se instala nas instituições estatais, que deveriam ser espaços do exercício do direito à igualdade, esses espaços segregam com ações violentas as quais acompanham os grupos marginalizados, impedindo estes de usufruírem seus direitos de cidadania.

Compreende-se que a violência simbólica é um meio de manter reféns grupos sociais discriminados em espaços cujas ações, por parte dos gestores, não dão conta de combater as ações discriminatórias ali existentes e vividas diariamente por indivíduos que ainda se encontram em fase de desenvolvimento.

E, em se tratando de crianças e adolescentes, esse processo discriminatório passa a ser mais agravante e cruel devido às consequências negativas que podem desencadear na fase adulta. E, por conseguinte, comprometer o futuro desses meninos e meninas que, ao buscarem melhores condições de enfrentamento das dificuldades sócio-econômicas nos espaços escolares, podem esbarrar em um fracasso social devido à ausência de preparo da gestão escolar no processo de enfretamento à discriminação étnica e cultural.

As afirmações dos gestores confirmam a urgência de ações para lidarem com as diversas questões étnico-raciais. Isso instiga a refletir sobre a formação inicial e continuada dos gestores, como também, a necessidade de inserir nos programas, como o HTPC, debates sobre a temática da discriminação.

Ressalta-se o caráter humanista do pensamento político-pedagógico de Paulo Freire e sua significativa contribuição na abordagem intercultural na educação, apontando e alertando sobre a necessidade de se atuar de forma sistemática diante de uma escola que está inserida numa sociedade racista e preconceituosa. Essa atuação vai influenciar a formação de novos comportamentos, desconstruindo os costumes que se incorporaram ao longo da história embasada em uma perspectiva etnocêntrica. Muito se fala, muito se discute, mas ao lançar o olhar para a prática pedagógica, pouco se observa no que se refere às ações conscientes e eficazes em combate às discriminatórias.

\section{Referências}

AGUESSY, H. Visões e percepções tradicionais. In: SOW, A. I. et al. Introdução à cultura africana. Lisboa: Edições 70, 1977, p. 95-136.

AGUIAR, J. C. T.; AGUIAR, F. J. F. Uma reflexão sobre o ensino de história e cultura afro-brasileira e africana e a formação de professores em Sergipe. Revista Fórum, Itabaina, v.7, jan-jun 2010. Disponível em: https://bit.ly/3gJh5wX. Acesso em 20 out. 2018.

ARENDT, H. Eichmann em Jerusalém: um relato sobre a banalidade do mal. São Paulo: Companhia das Letras, 1999.

AZEVEDO, C. B. Educação para as relações étnico-raciais e ensino de história na educação básica. 2011. Disponível em: https://bit.ly/3glvx6Q. Acesso em: 17 abr. 2018. 
BARDIN, L. Análise de conteúdo. Lisboa, Portugal: Edições 70, 2016.

BASTIANI, M. L. Escola alternativa: pedagogia da participação. Florianópolis: Cidade Futura; 2000.

BRANT, L. Diversidade cultural: globalização e culturas locais - dimensões, efeitos e perspectivas. São Paulo: Escrituras Editora: Instituto Pensarte, 2005.

BRASIL. Diretrizes curriculares nacionais para a educação das relações étnico-raciais e para o ensino de história e cultura afro-brasileira e africana. Brasília, DF: MEC, 2004

BRASIL. Ministério da educação e cultura. Secretaria do CEAD. Educação africanidades Brasil. Brasília: MEC, 2006.

BRASIL. Ministério da Educação. Plano Nacional de Implementação das diretrizes curriculares nacionais para educação das relações étnico-raciais e para o ensino de história e cultura afrobrasileira e africana. Secretaria Especial de Políticas de Promoção da Igualdade Racial. Subsecretaria de políticas de Ações afirmativas. Brasília: MEC, 2009, p. 22.

CANDAU, V. M. Prefácio. In: ANDRADE, M. (Org.). A diferença que desafia a escola: a prática pedagógica e a perspectiva intercultural. Rio de janeiro: Quartet, 2009.

CARENO, M. F. Desigualdades raciais em educação no Brasil. Pesquisa e educa. Santos, v. 1, n. 2, p. 129134, jul - dez 2009. Disponível em: https://bit.ly/35IXPZU. Acesso em nov. de 2018.

CARVALHO, D. M. S.; FRANÇA, D. X. Estratégias de enfrentamento do racismo na escola: uma revisão integrativa. Educação \& formação. Fortaleza, v. 4, n. 12, p. 148-168, set./out. 2019.

CURY, C. R. J. O Direito à Educação. Disponível em: https://bit.ly/2TRE2Vq. Acesso em: 17 abr. 2018.

FREIRE, . Pedagogia do oprimido. Rio de Janeiro: Paz e Terra, 1987.

GADOTTI, M. Pedagogia da práxis. São Paulo: Cortez, 1995.

LIMA, M. A África na sala de aula. In: Nossa história, n 4. Rio de Janeiro: Fundação Biblioteca Nacional, 2004, p. 84-87.

LOPES, V. N. Racismo, preconceito e discriminação. In: MUNANGA, K. (Org.). Superando o racismo na escola. 2 ed. Brasília: MEC - Secretaria da Educação Continuada, Alfabetização e Diversidade, 2005, p. 185-20.

LÜCK, H. A evolução da gestão educacional, a partir de mudança paradigmática. Revista gestão em rede, n. 3, p. 13-18, nov. 1997.

LÜDKE, M; ANDRÉ, M. E. D. A. Pesquisa em educação: abordagens qualitativas. São Paulo, EPU, 1986.

MARCONDES, M. I. Freire como autor internacional: pedagogia do oprimido em língua inglesa publicada 50 anos atrás. Revista e-Curriculum, v. 16, n. 4, dez. 2018. Disponível em: https://bit.ly/3gSZDVk. Acesso em: 11 mar. 2020.

MUNANGA, K. Superando o racismo na escola. 2 ed. Brasília: MEC, 2005.

PEREIRA, E. A. Malungos na escola: questões sobre culturas afrodescendentes e educação. São Paulo: Editora Paulinas, 2007. 
PEROZA, J.; DA SILVA, C. P.; AKKARI, A. Paulo Freire e a diversidade cultural: um humanismo políticopedagógicos para a transculturalidade na educação. Reflexão e Ação, Santa Cruz do Sul, v. 21, n. 2, p. 461-481, dez. 2013. Disponível em: https://bit.ly/3gLwIDK. Acesso em: 11 mar. 2020.

RAMIREZ, G. P. L. Museu como espaço de ressignificação cultural e religiosa no processo de educação informal. In: JUSTUS, M. B. (Org.). Formação de professores e a condição do trabalho docente 2. Ponta Grossa: Atena, 2019, p. 242-248.

RAMIREZ, G. P. L.; GONÇALVES, B. P.; ANDRADE, L. F. Valorização de identidade cultural afrobrasileira em uma escola quilombola. In: SILVA, D.; SOUZA, I. P.; JORGE, W. J. (Orgs.). Inclusão escolar: para além da educação especial. Maringá: Uniedusul Editora, 2019, p. 61-68.

RAMIREZ, G. P. L.; SILVA, A. D. Educação e religiosidade, uma reflexão sobre a diversidade cultural das comunidades tradicionais no Brasil. In: PURIFICAÇÃO, M. M.; CATARINO, E. M.; SANTANA, L. J. (Orgs.). Ampliação e aprofundamento dos conhecimentos teológicos das religiões. Ponta Grossa: Atena, 2021, p. 25-31.

SILVA, A. C. A Desconstrução da Discriminação no Livro Didático. In: MUNANGA, K. (Org.). Superando o racismo na escola. Brasília: Ministério da Educação, Secretaria de Educação Continuada, Alfabetização e Diversidade, 2005.

SILVA, A. C. A discriminação do negro no livro didático. Salvador: CEAO; CED, 1995.

SILVA, L. D.; RAMIREZ, G. P. L. A questão afro-brasileira sob a perspectiva da gestão escolar em nível básico na cidade de Cuiabá-MT. Momento Diálogos em Educação, v. 29, n. 3, p. 52-66, set.- dez. 2020.

SOUZA, L. A. F. Sociologia da violência e do controle social. Curitiba: lesde Brasil S.S., 2008.

TRIVIÑOS, A. N. S. Introdução à pesquisa em Ciências Sociais: a pesquisa qualitativa em educação. São Paulo: Atlas, 1987.

UNESCO. Convenção relativa à Luta contra a Discriminação no campo do Ensino. Disponível em: <https://bit.ly/3gJs1KX>. Acesso em: 15 out. 2018.

VALENTE, A. L. E. F. Ser negro no Brasil hoje. São Paulo: Moderna, 1994.

VASCONCELLOS, C. S. Coordenação do trabalho pedagógico: do projeto político pedagógico ao cotidiano da sala de aula. São Paulo: Libertad, 2002.

VAZ, M. C. D. Gestão participativa. Disponível em: https://bit.ly/3qclLxj. Acesso em 20 maio 2018. 